\title{
Corrigendum: Skeletal Muscle Fiber Size and Gene Expression in the Oldest-Old With Differing Degrees of Mobility
}

\author{
Fabio Naro ${ }^{1}$, Massimo Venturelli ${ }^{2}$, Lucia Monaco ${ }^{3}$, Luana Toniolo ${ }^{4}$, Ettore Muti ${ }^{5}$, \\ Chiara Milanese ${ }^{2}$, Jia Zhao ${ }^{6,7,8}$, Russell S. Richardson ${ }^{6,7,8}$, Federico Schena ${ }^{2}$ and \\ Carlo Reggiani ${ }^{4,9 *}$
}

' Department of Anatomical, Histological, Forensic and Orthopedic Sciences, Sapienza University of Rome, Rome, Italy, ${ }^{2}$ Department of Neurosciences, Biomedicine and Movement Sciences, University of Verona, Verona, Italy, ${ }^{3}$ Department of Physiology and Pharmacology, Sapienza University of Rome, Rome, Italy, ${ }^{4}$ Department of Biomedical Sciences, University of Padova, Padua, Italy, ${ }^{5}$ Monsignor Arrigo Mazzali Foundation, Mantova, Italy, ${ }^{6}$ Division of Geriatrics, Department of Internal Medicine, The University of Utah, Salt Lake City, UT, United States, ${ }^{7}$ Department of Nutrition and Integrative Physiology, The University of Utah, Salt Lake City, UT, United States, ${ }^{8}$ Geriatric Research, Education, and Clinical Center, George E. Whalen VA Medical Center, Salt Lake City, UT, United States, ${ }^{9}$ Institute for Kinesiology Research, Science and Research Center of Koper, Koper, Slovenia

Keywords: aging, oldest-old, physical activity, muscle atrophy, single muscle fibers, myonuclei, gene expression

\section{A Corrigendum on}

\section{OPEN ACCESS}

Edited and reviewed by: Bradley Elliott, University of Westminster, United Kingdom

*Correspondence: Carlo Reggiani

carlo.reggiani@unipd.it

Specialty section:

This article was submitted to Striated Muscle Physiology,

a section of the journal

Frontiers in Physiology

Received: 06 January 2020 Accepted: 06 February 2020 Published: 25 February 2020

Citation:

Naro F, Venturelli M, Monaco $L$, Toniolo L, Muti E, Milanese C, Zhao J, Richardson RS, Schena F and Reggiani C (2020) Corrigendum: Skeletal Muscle Fiber Size and Gene Expression in the Oldest-Old With

Differing Degrees of Mobility.

Front. Physiol. 11:127.

doi: 10.3389/fphys.2020.00127
Skeletal Muscle Fiber Size and Gene Expression in the Oldest-Old With Differing Degrees of Mobility

by Naro, F., Venturelli, M., Monaco, L., Toniolo, L., Muti, E., Milanese, C., et al. (2019). Front. Physiol. 10:313. doi: 10.3389/fphys.2019.00313

In the original article, there was an error in citing a paper concerning the impact of physical activity on motoneuron survival: Dranseika et al. (2016) was cited instead of Piasecki et al. (2016). A correction has been made to second paragraph of the Introduction, which reads as follows:

The conundrum of greatly diminished muscle size and function, while individual muscle fiber size and function are preserved, may potentially be explained by a loss of muscle fibers. In this respect, the neural system plays a pivotal role. Initially, with progressive motoneuron death and fiber denervation, and, then, by the disappearance of the denervated fibers or, possibly, by partial reinnervation of the surviving fibers by sprouting of slow motoneurons (Delbono, 2003, 2011; Payne and Delbono, 2004; Aagaard et al., 2010; Reid et al., 2012; Venturelli et al., 2018). Interestingly, it is still debated whether the loss of motoneurons can be slowed down by regular physical activity [see Power et al. (2010) in favor and Piasecki et al. (2016) against this view]. Unfortunately, the direct assessment of the impact of neural events on muscle fiber size and number during advanced age and disuse is somewhat complicated (Doherty et al., 1993). However, the comparison between the force developed during maximal voluntary contraction (MVC) and electrically stimulated contraction helps to estimate the contribution of reduced neural drive to muscle deconditioning (Venturelli et al., 2015). Furthermore, the evaluation of in vivo single twitch kinetics may further contribute to understand the functional condition of skeletal muscle, as the maximal rates of force development are clearly different among slow and fast motor units (Mero et al., 1991). Unfortunately, information regarding single twitch kinetics in the oldest-old is sparse.

The authors apologize for this error and state that this does not change the scientific conclusions of the article in any way. The original article has been updated. 


\section{REFERENCES}

Aagaard, P., Suetta, C., Caserotti, P., Magnusson, S. P., and Kjaer, M. (2010). Role of the nervous system in sarcopenia and muscle atrophy with aging: strength training as a countermeasure. Scand. J. Med. Sci. Sports 20, 49-64. doi: 10.1111/j.1600-0838.2009.01084.x

Delbono, O. (2003). Neural control of aging skeletal muscle. Aging Cell 2, 21-29. doi: 10.1046/j.1474-9728.2003.00011.x

Delbono, O. (2011). Expression and regulation of excitation-contraction coupling proteins in aging skeletal muscle. Curr. Aging Sci. 4, 248-259. doi: 10.2174/1874609811104030248

Doherty, T. J., Vandervoort, A. A., Taylor, A. W., and Brown, W. F. (1993). Effects of motor unit losses on strength in older men and women. J. Appl. Physiol. 74, 868-874. doi: 10.1152/jappl.1993.74.2.868

Mero, A., Jaakkola, L., and Komi, P. V. (1991). Relationships between muscle fibre characteristics and physical performance capacity in trained athletic boys. J. Sports Sci. 9, 161-171. doi: 10.1080/02640419108 729877

Payne, A. M., and Delbono, O. (2004). Neurogenesis of excitation-contraction uncoupling in aging skeletal muscle. Exerc. Sport Sci. Rev. 32, 36-40. doi: 10.1097/00003677-200401000-00008

Piasecki, M., Ireland, A., Stashuk, D., Hamilton-Wright, A., Jones, D. A., and McPhee, J. S. (2016). Age-related neuromuscular changes affecting human vastus lateralis. J. Physiol. 594, 4525-4536. doi: 10.1113/JP271087
Power, G. A., Dalton, B. H., Behm, D. G., Vandervoort, A. A., Doherty, T. J., and Rice, C. L. (2010). Motor unit number estimates in masters runners: use it or lose it? Med. Sci. Sports Exerc. 42, 1644-1650. doi: 10.1249/MSS.0b013e3181d6f9e9

Reid, K. F., Doros, G., Clark, D. J., Patten, C., Carabello, R. J., Cloutier, G. J., et al. (2012). Muscle power failure in mobility-limited older adults: preserved single fiber function despite lower whole muscle size, quality and rate of neuromuscular activation. Eur. J. Appl. Physiol. 112, 2289-2301. doi: 10.1007/s00421-011-2200-0

Venturelli, M., Reggiani, C., Richardson, R. S., and Schena, F. (2018). Skeletal muscle function in the oldest-old: the role of intrinsic and extrinsic factors. Exerc. Sport Sci. Rev. 46, 188-194. doi: 10.1249/JES.0000000000000155

Venturelli, M., Saggin, P., Muti, E., Naro, F., Cancellara, L., Toniolo, L., et al. (2015). In vivo and in vitro evidence that intrinsic upper- and lower-limb skeletal muscle function is unaffected by ageing and disuse in oldest-old humans. Acta Physiol. 215:14. doi: 10.1111/apha.12524

Copyright (C) 2020 Naro, Venturelli, Monaco, Toniolo, Muti, Milanese, Zhao, Richardson, Schena and Reggiani. This is an open-access article distributed under the terms of the Creative Commons Attribution License (CC BY). The use, distribution or reproduction in other forums is permitted, provided the original author(s) and the copyright owner(s) are credited and that the original publication in this journal is cited, in accordance with accepted academic practice. No use, distribution or reproduction is permitted which does not comply with these terms. 